\title{
Technical Feasibility of Creating a Beach Grain Size Database
with Citizen Scientists a Beach Grain Size Database
with Citizen Scientists
}

US Army Corps
of Engineers

by Brian C. McFall, David L. Young, Kelsey A. Fall, Douglas R. Krafft, Shelley J. Whitmeyer, Alesha E. Melendez, Daniel Buscombe

PURPOSE: The goal of this Coastal and Hydraulics Engineering Technical Note (CHETN) is to investigate the feasibility of collecting beach grain size information with images collected by citizen scientists to build a globally accessible database.

INTRODUCTION: Engaging citizen scientists in scientific information collection through crowdsourcing has become a more popular and cost-effective way to collect large amounts of data while increasing interest in the research through public engagement (Irwin 2018). Citizen scientists equipped with their personal smartphones allow for very large datasets to be collected that would otherwise be financially or logistically impossible (Bauer-Civiello et al. 2018; Gura 2013; Harley et al. 2019). Additionally, it provides an opportunity to educate and engage the general public.

Sediment grain size information collected through crowdsourcing could be particularly helpful in preliminary studies where sediment grain size information is not easily accessible or in large-scale studies where the sediment grain size is spatially variable. This information could be used in many different types of beach studies including the preliminary estimations of the depth of closure (Hallermeier 1981), application in the Sediment Mobility Tool (McFall et al. 2016; McFall and Brutsché 2018), or in large-scale shoreline change studies (Bauer-Civiello et al. 2018; Luijendijk et al. 2018; Harley et al. 2019). Additionally, most coastal projects and studies use coastal morphological models that assume a single, well-sorted grain size that is determined from a limited number of sediment samples collected in the field and processed in a laboratory, while it is known that the grain size varies spatially and temporally (Gallagher et al. 2011; Prodger et al. 2016). Soulsby (1997) identified the grain size as having the largest uncertainty of any parameter for sediment transport models. Having a spatially and temporally dense grain size database would be very beneficial for quantifying the uncertainty of coastal engineering projects.

The present study investigates the feasibility of collecting sediment grain size information at sandy beaches in the United States by engaging citizen scientists. Techniques to estimate the sediment grain size from image data and identifying the sediment sample location are examined for accuracy. Additionally, the potential benefits of collaborating with citizen scientists are explored.

GRAIN SIZE ANALYSIS TECHNIQUES: The most critical component of this feasibility study is to identify an efficient method to accurately estimate the sediment grain size on various sandy beaches. Four categories of analysis are considered: geometrical analysis, statistical analysis, machine learning, and physically shipping sediment samples for analysis. The three image analysis techniques (geometrical analysis, statistical analysis, and machine learning) are compared to sieve analysis following the ASTM C136 procedure with sieve sizes ranging from $0 \phi$ to $4 \phi$ in $1 / 2 \phi$ increments. Images collected for analysis were collected with cell phones with built-in 12-13 megapixel cameras and a US coin for scaling. A more thorough examination of the different 
techniques is described below. The desired percent error for the image processing techniques is less than $25 \%$ for the median grain size $\left(d_{50}\right)$. A $25 \%$ error in the $d_{50}$ for a grain size of $0.3 \mathrm{~mm}^{*}$ would result in a $20 \%$ difference in the calculated longshore transport according to the Costal Engineering Research Center (CERC) equation with a breaking wave height of $2 \mathrm{~m}$, which is reasonable for morphological modeling (USACE 2002). A desired percent error of less than $25 \%$ for the $d_{50}$ is precise considering that the cross-shore sorting of sediment on the subaerial beach can vary the grain size by more than $200 \%$ (Bascom 1951).

Geometrical Analysis. Geometrical analysis (GA) applies digital image processing techniques to identify and separate sediment grains within an image into discrete objects and then estimates the size of objects or grains individually. A semi-automated image analysis routine was developed to identify and measure sediment grain size within the cell phone images. The routine employs algorithms from the MATLAB Image Processing Toolbox. The algorithm consists of three main parts: (1) preprocessing (e.g., load in image and select region to process), (2) image processing via thresholding to identify grains, and (3) calculation of grain size distribution.

An interactive graphical user interface (GUI) shown in Figure 1 was developed to guide users through the processing. Users load the image, enter the image scale ( $\mathrm{mm} /$ pixel), and select a region within the image that is in focus and does not include the object used for scale. Cell phone images are collected as colored or red-green-blue images in which each pixel has a value describing the red, green, and blue component. The aim of image processing is to generate a binary image in which pixels are characterized with just two intensity values, 0 to denote background and 1 to indicate foreground or a grain. The selected region is first converted to an 8-bit integer grayscale image in which each pixel is assigned a single value from 0 to 255 to describe its brightness or intensity. It is then converted to a binary image using a segmentation technique called thresholding. Thresholding differentiates particles from the background based on grayscale pixel intensity $\left(I_{(\mathrm{x}, \mathrm{y})}\right)$ relative to a defined intensity threshold, $T$ (Gonzalez et al. 2004). Segmentation with thresholding can be done with one threshold for the entire image (e.g., global thresholding [GT]) or with a locally varying threshold in which each pixel gets an individual threshold value (e.g., local threshold [LT]). The GT routine applies the Otsu (1979) method, an automated cluster-based approach. The LT method separates the image into $0.5 \mathrm{~mm}$ sections, and the intensity threshold for a given pixel $\left(T_{(x, y)}\right)$ is defined as the Gaussian weighted mean of the intensities of the pixels within the local $0.5 \mathrm{~mm}$ region. In both methods, pixels with intensities equal to or exceeding the threshold value $(T$ or $T(x, y))$ are characterized as grain pixels while those with intensities less than $T$ or $T_{(x, y)}$ are defined as background. LT is more computationally expensive, but it tends to do better in cases with uneven background illumination (Gonzalez et al. 2004). The interactive GUI makes it simple to try both approaches and determine the one that performs better. To deal with particle overlap and separate touching grains, the binary image is further refined using watershed segmentation (Gonzalez et al. 2004; Graham et al. 2005; Kornilov and Safornov 2018). Watershed segmentation is a classical algorithm for separating objects in an image. Finally, position and size for each identified grain are calculated, and a grain size distribution is generated.

\footnotetext{
${ }^{*}$ For a full list of the spelled-out forms of the units of measure used in this document, please refer to US Government Publishing Office Style Manual, 31st ed. (Washington, DC: US Government Publishing Office, 2016), 248-52, https://www.govinfo.gov/content/pkg/GPO-STYLEMANUAL-2016/pdf/GPO-STYLEMANUAL-2016.pdf.
} 


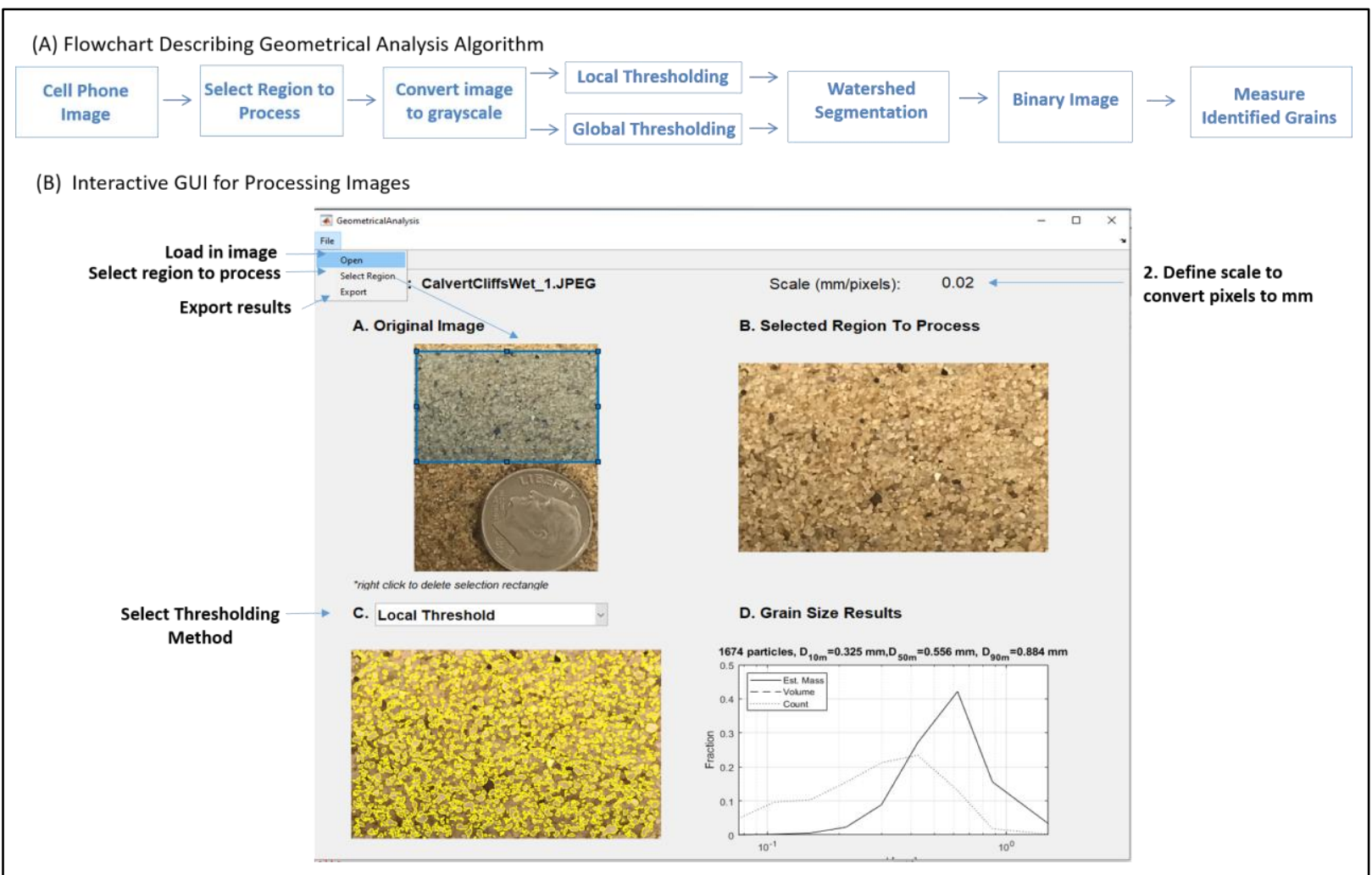

Figure 1. (A) Flowchart describing the image processing GA algorithm. (B) Screen shot of the interactive GUI developed to guide users through the processing procedure.

The GA algorithm was evaluated using cell phone images of sand from four beaches: one in a bay on the east coast (Calvert Cliffs State Park, Maryland) and three along the Gulf Coast of Mississippi (Ocean Springs, Biloxi, and Gulfport). The biggest challenge applying GA analysis to cell phone images was capturing photos at adequate resolution to distinguish edges of grains. Ideal resolution for sand is $0.01-0.03 \mathrm{~mm} /$ pixel. Median particle size $\left(d_{50}\right)$ estimated from GA are compared to $d_{50}$ determined from sieve analysis in Table 1 . In all cases, the GA $d_{50}$ are $1.2-1.6$ times higher than $d_{50}$ determined from sieve analysis. Differences between sieve data and GA are expected. With sieving, size is based upon the minimum particle axis while GA characterizes size of individual grains in terms of the equivalent spherical diameter or the diameter of a sphere that has the same area as the identified grain (Sime and Ferguson 2003; Li et al. 2005). Additionally, GA involves significantly fewer observations (e.g., Li et al. 2005, Figure 2A). Overall, larger grains were better resolved than smaller grains, some touching grains were not separated, and some grains were only partially resolved. The low mean error in Table 1 for Ocean Springs, MS, and Gulfport, MS, is due to bias associated with the partially resolved grains as shown in Figure 2A. 
Table 1. GA grain size analysis results compared with the sieve-estimated $d_{50}$ for field images of sediment.

\begin{tabular}{|c|c|c|c|c|c|c|c|}
\hline Location & $\begin{array}{l}\text { Material } \\
\text { State }\end{array}$ & $\begin{array}{c}\text { \# of } \\
\text { Images }\end{array}$ & $\begin{array}{c}\text { \# of } \\
\text { Particles } \\
\text { Identified }\end{array}$ & $\begin{array}{c}\text { mm/pixel } \\
\text { range }\end{array}$ & $\begin{array}{c}\text { GA } d_{50} \\
(\mu \mathrm{m})\end{array}$ & $\begin{array}{l}\text { Sieve } d_{50} \\
\quad(\mu \mathrm{m})\end{array}$ & $\begin{array}{c}\text { Mean } \\
\text { Error in } \\
d_{50}\end{array}$ \\
\hline Calvert Cliffs, MD & Wet & 3 & 3290 & $0.01-0.02$ & $529 \pm 7$ & 408 & $29.7 \%$ \\
\hline Biloxi, MS & Wet & 2 & 3539 & $0.02-0.03$ & $484 \pm 17$ & 295 & $64.1 \%$ \\
\hline Ocean Springs, MS & Dry & 1 & 6566 & 0.02 & 367 & 300 & $22.3 \%$ \\
\hline Gulfport, MS & Dry & 1 & 1462 & 0.01 & 317 & 263 & $20.5 \%$ \\
\hline Total/Mean & & 7 & 3714 & 0.02 & - & - & $34.2 \%$ \\
\hline
\end{tabular}

These GA results prompted a second sampling method in which the sediment sample was dried in an oven and a small spoonful of sediment was carefully dispersed, in an effort to separate grains, on a black background as seen in Figure 2B. For the coarsest grained sample tested, Calvert Cliffs, MD, there was little difference between the two sampling methods, but the separated grains method did better resolving grains in other cases as seen in Table 2 . Unfortunately with this method, even fewer grains are observed. Additionally, it is more tedious, so it may not be ideal for the citizen scientist application.

Table 2. GA grain size analysis results compared with the sieve-estimated $d_{50}$ for images of separated grains on a black background.

\begin{tabular}{|l|c|c|c|c|c|c||}
\hline \hline Location & $\begin{array}{c}\text { \# of } \\
\text { Images }\end{array}$ & $\begin{array}{c}\text { \# of Particles } \\
\text { Identified }\end{array}$ & $\begin{array}{c}\text { mm/pixel } \\
\text { Range }\end{array}$ & $\begin{array}{c}\text { GA } \boldsymbol{d}_{50} \\
(\boldsymbol{\mu m})\end{array}$ & $\begin{array}{c}\text { Sieve } \boldsymbol{d}_{50} \\
(\boldsymbol{\mu m})\end{array}$ & $\begin{array}{c}\text { Mean Error in } \\
\boldsymbol{d}_{\mathbf{5 0}}\end{array}$ \\
\hline Calvert Cliffs, MD & 4 & 5792 & $0.01-0.03$ & $506 \pm 5$ & 408 & $24.0 \%$ \\
\hline Biloxi, MS & 4 & 1265 & 0.01 & $304 \pm 1$ & 295 & $3.1 \%$ \\
\hline Ocean Springs, MS & 3 & 741 & 0.01 & $302 \pm 10$ & 300 & $0.7 \%$ \\
\hline Gulfport, MS & 4 & 1652 & 0.01 & $326 \pm 8$ & 263 & $24.0 \%$ \\
\hline Total/Mean & 15 & 2363 & 0.01 & - & - & $13.0 \%$ \\
\hline
\end{tabular}




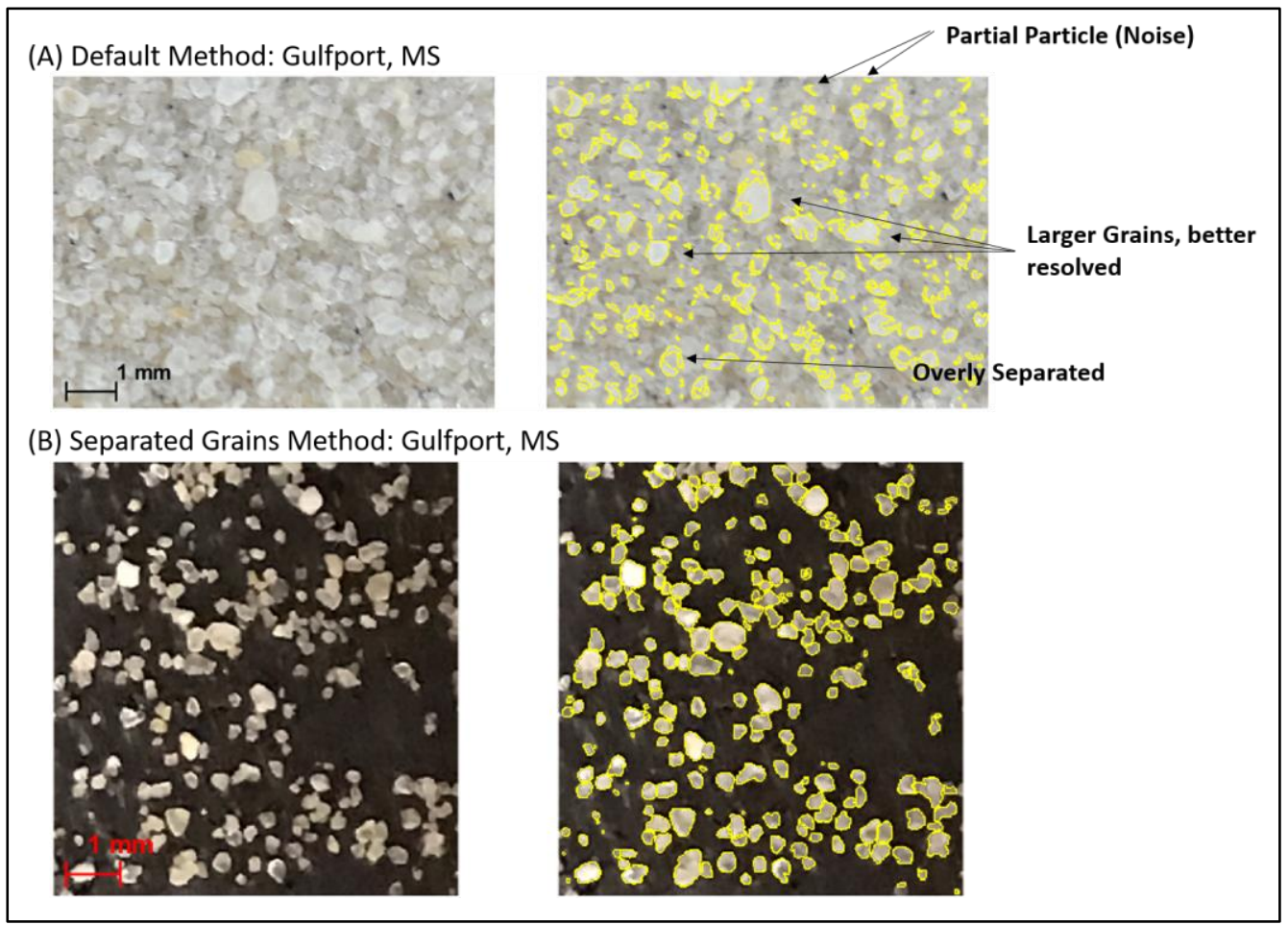

Figure 2. GA results for images of sediments collected at Gulfport, MS, using (A) the default method with in situ field images and the (B) separated grains method on a black background. The images on the left are the raw images, and the images on the right show the outline of grains identified by GA highlighted in yellow.

Statistical Analysis. Statistical methods characterize grain size using a measure of image texture. Approaches have included auto-correlation (Rubin 2004; Warrick et al. 2009), semivariance (Carbonneau et al. 2004; 2005), and fractals (Buscombe and Masselink 2009), among others. Statistical methods do not require identification of individual grains but often require some calibration, which restricts their versatility.

The wavelet approach of Buscombe (2013) relies on spectral analysis of the image to identify dominant spatial wavelengths, which is used to estimate grain size, but utilizes a wavelet-derived power spectra, rather than a Fourier-derived one as in Buscombe et al. (2010). Unlike Fourierderived spectral analysis, wavelet analysis does not require stationary or statistically homogeneous images. It is therefore less sensitive to the number of grains in the image or the preferred orientation of the grains and is better suited for analyzing poorly sorted sediments (Buscombe 2013). Perhaps most critical for field-obtained images at disparate locations, it does not require calibration for sediment type or geographic position. The wavelet-based grain size analysis methodology is more thoroughly discussed in Buscombe (2013).

A Python implementation of the Buscombe (2013) wavelet-based grain size estimation tool is freely available on GitHub at https://github.com/dbuscombe-usgs/pyDGS. The python package is referred to as pyDGS, and it requires only the name and path to the image of the sediment sample to run. The spatial resolution of the image is one of several optional inputs; however, if it is not specified, the grain size estimates are returned in pixels. All optional inputs are set to default for 
the results presented herein unless otherwise specified. The Python analysis returns the $d_{50}$, standard deviation, skewness, and kurtosis of the grain size distribution, among other parameters.

The wavelet analysis used in pyDGS may be susceptible to influence by interrogation window size as larger windows may identify lower-frequency harmonics that will skew the $d_{50}$ results. Consequently, the tool was not solely applied to the full image of the sediment sample. A subwindowing technique was employed, whereby the tool was also applied to a series of sub-windows with identical square image size. The pixel sizes for the square sub-windows ranged from 500 to 1600 pixels, in increments of 100 pixels. Each sub-window was generated by shifting the $\mathrm{x} / \mathrm{y}$ pixel position of the upper left-hand corner of the sub-window 300 pixels right/down from the upper left-hand corner of the previous sub-window. The first sub-window begins in the upper left-hand corner of the image - pixel coordinates $(\mathrm{x}=0, \mathrm{y}=0)$. The windowing schema is represented pictorially in Figure 3. Non-square sub-windows were not retained for analysis. The Python grain size estimation tool was applied to each sub-window for all tested window sizes, as well as the full-size image.

This sub-windowing technique allows for the interrogation of the variability in the $d_{50}$ estimate with changing image (or sub-window) size within the Python grain size estimation tool. Figure 4 shows the variation in estimated $d_{50}$ for an image taken of dry surface sand in Gulfport, MS.

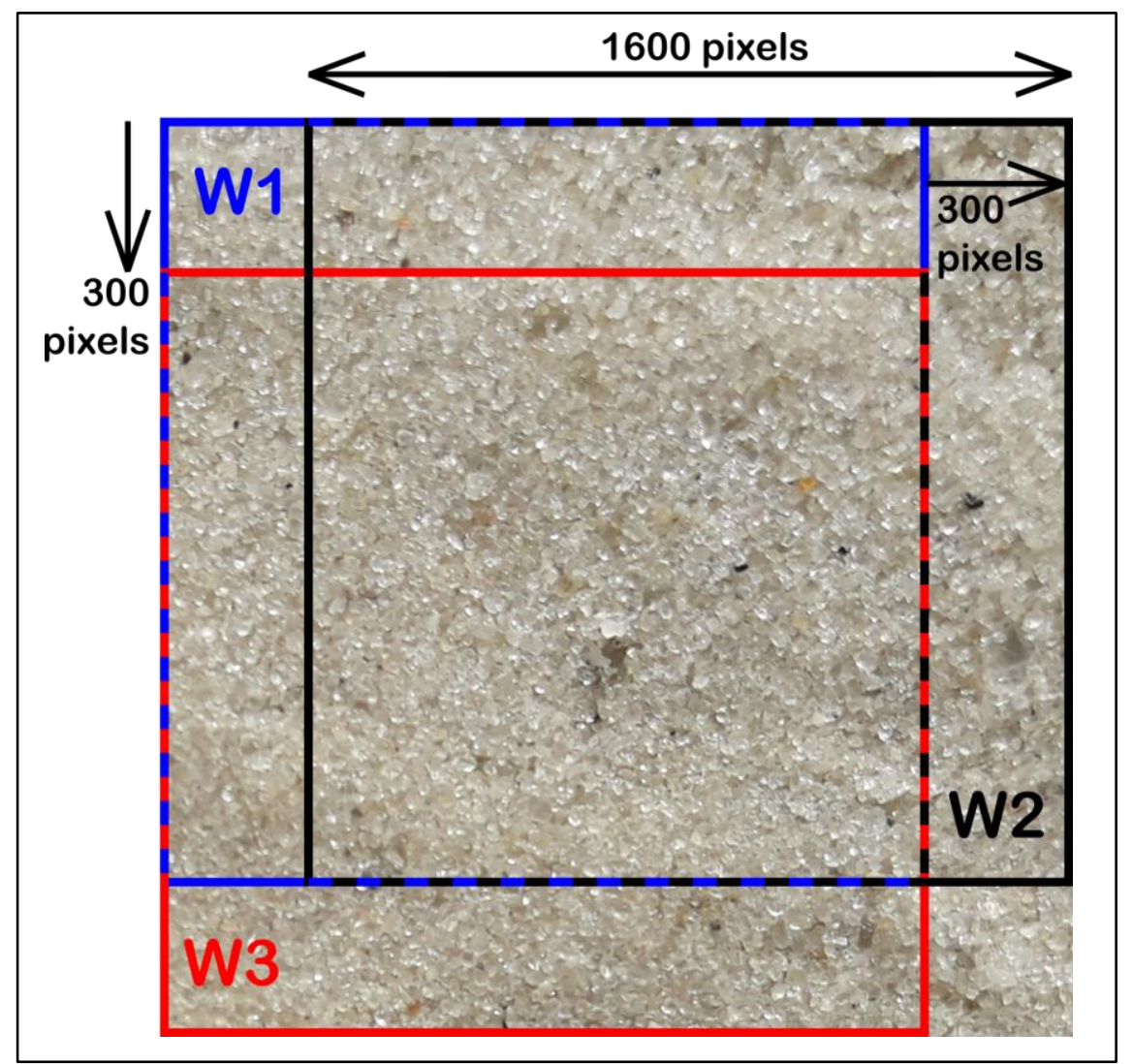

Figure 3. Representation of the windowing schema for $1600 \times 1600$ pixel sub-windows from a Biloxi, MS, dry surface image. 


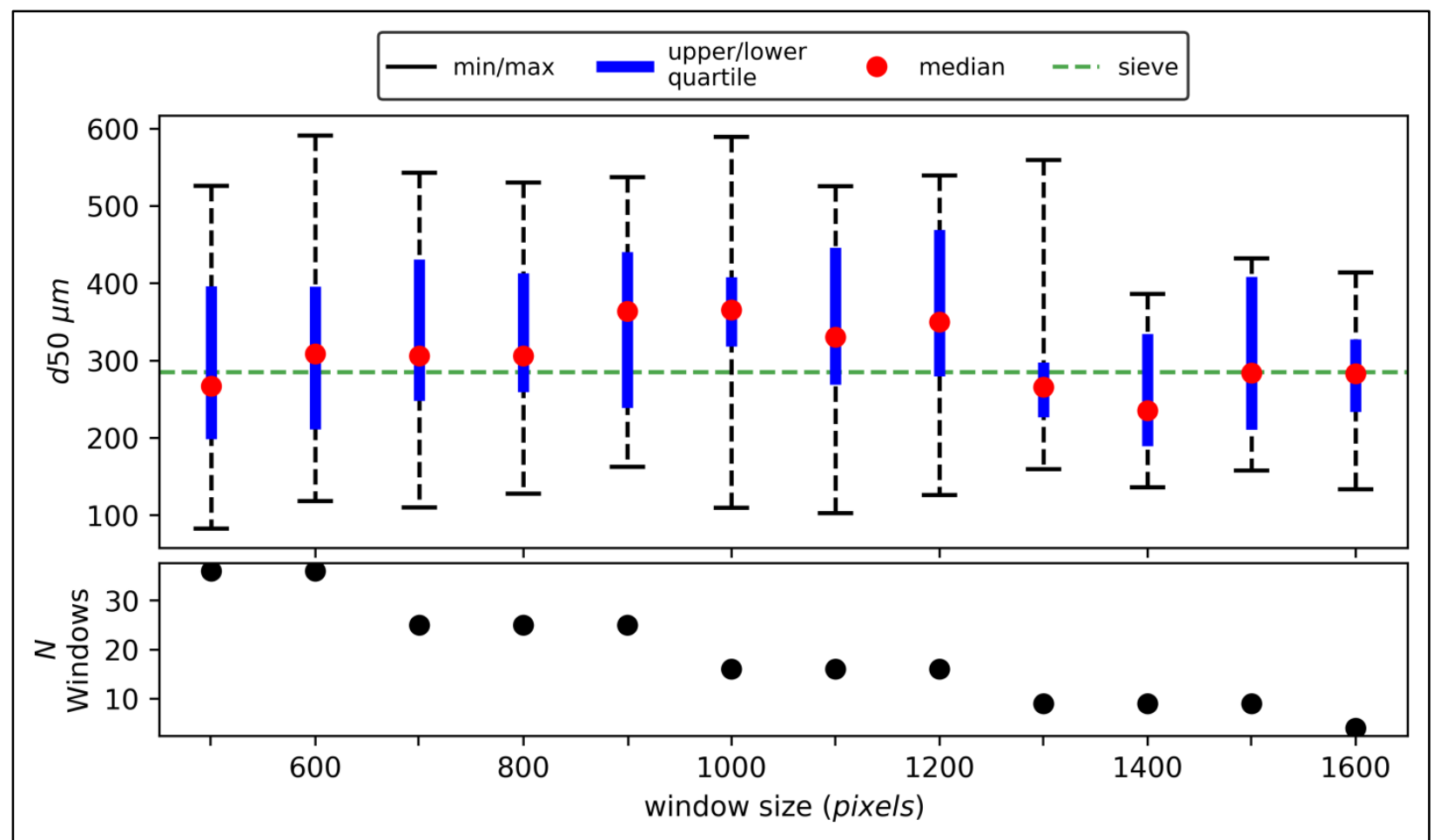

Figure 4. Top panel - variation in estimated $d_{50}$ with variable window size for an image taken of dry surface sand in Gulfport, MS - the median (red), $\min / \max$ (black), and upper/lower quartile (blue) of the estimated $d_{50}$ values across all the image sub-windows are reported. The $d_{50}$ of this sample as measured by sieve analysis is shown as a green dashed line. Bottom panelnumber $(\mathrm{N})$ of sub-windows analyzed for each window size.

Figure 4 shows that the results of the Python wavelet-based grain size estimator do not appear to vary with changing image size. However, it does suggest that the quality of the results may still benefit from a windowed approach to the analysis. In general, the median of the reported $d_{50}$ 's across all sub-windows appears to yield results very close to the sieve-measured $d_{50}$. In contrast, the comparatively large spread in the $\mathrm{min} / \mathrm{max}$ (and to a lesser extent, the upper and lower quartile) values suggests that the results from individual sub-windows are susceptible to larger errors.

Table 3 shows the comparison of the aggregated pyDGS grain size analysis results to the sieveestimated $d_{50}$ for various sites and sediment conditions. Sediment samples were collected from three sites (Biloxi, MS; Gulfport, MS; and Calvert Cliffs, MD). The reported pyDGS-estimates of $d_{50}$ in Table 3 are the median $d_{50}$ estimates across all sub-windows of all images characterizing a particular sediment sample location/material state. 


\begin{tabular}{|l|c|c|c|c|c|c||}
\hline \multicolumn{6}{||}{ Table 3. pyDGS grain size analysis results compared with the sieve-estimated $\boldsymbol{d}_{50}$} \\
\hline \hline Location & $\begin{array}{c}\text { Material } \\
\text { State }\end{array}$ & $\begin{array}{c}\text { \# of } \\
\text { Images }\end{array}$ & $\begin{array}{c}\text { mm/pixel } \\
\text { Range }\end{array}$ & $\begin{array}{c}\text { pyDGS } \boldsymbol{d}_{50} \\
(\boldsymbol{\mu m})\end{array}$ & $\begin{array}{c}\text { Sieve } \boldsymbol{d}_{50} \\
(\boldsymbol{\mu m})\end{array}$ & $\begin{array}{c}\text { Mean Error } \\
\text { in } \boldsymbol{d}_{50}\end{array}$ \\
\hline Biloxi, MS & Dry & 4 & $0.01-0.05$ & 468 & 259 & $80.7 \%$ \\
\hline Biloxi, MS & Dry/Surface & 4 & $0.01-0.04$ & 367 & 267 & $37.5 \%$ \\
\hline Biloxi, MS & Wet & 4 & $0.02-0.06$ & 269 & 295 & $8.8 \%$ \\
\hline Gulfport, MS & Dry & 5 & $0.01-0.04$ & 286 & 263 & $8.7 \%$ \\
\hline Gulfport, MS & Dry/Surface & 5 & $0.01-0.05$ & 229 & 283 & $19.1 \%$ \\
\hline Gulfport, MS & Wet & 4 & 0.01 & 338 & 438 & $22.8 \%$ \\
\hline Calvert Cliffs, MD & Dry & 5 & $0.02-0.05$ & 484 & 304 & $59.2 \%$ \\
\hline Calvert Cliffs, MD & Wet & 4 & $0.01-0.04$ & 630 & 408 & $54.4 \%$ \\
\hline Total/Mean & - & 33 & 0.03 & - & - & $36.4 \%$ \\
\hline
\end{tabular}

The percent error values in Table 3 indicate that pyDGS is approximating the sieve-measured $d 50$ well for the majority of samples, with estimated errors less than $40 \%$ for more than half the samples. These errors are similar to the results in Buscombe (2013), which had less than 50\% root mean square error for natural sediments. The pyDGS algorithm performs markedly superior in estimating the grain size of the Gulfport, MS, soil samples relative to the other two regions (Biloxi, MS, and Calvert Cliffs, MD). This may be due to better lighting in the image.

Machine Learning Analysis. The SediNet framework (Buscombe 2020) uses machine learning to estimate grain characteristics. Models are trained using example images and associated grain size percentiles computed from sieve analysis. The model uses a deep neural network framework to learn the mapping between the image and sieve data and extracts only the image features that covary strongly with grain size. Whereas the wavelet method offers a generic means to estimate grain size, SediNet allows customization to specific environments, such as ocean beaches. The model was trained using 63 images collected from the seven sites shown in Table 4. Each image was taken from a different altitude, thus had a unique scaling, and had an associated grain size distribution from a sieve analysis on a physical sample collected from the site. Each image had a quarter dollar coin (24.26 $\mathrm{mm}$ in diameter) in the field-of-view for scaling. Blurred imagery and imagery of very wet sand were discarded. Of the remaining focused images of relatively dry sand, several $1024 \times 1024 \times 3$ pixel sub-windows were cropped, avoiding the coin, other objects, strong shadows, etc. Those images were also horizontally flipped to augment the dataset, providing the machine-learning model more labeled image examples to train with. This process of sub-windows and flipping images resulted in 517 total images for training and testing the model, each with a scale in $\mathrm{mm} /$ pixel. For each image, three percentiles of the cumulative grain size distribution, namely the 10th, 50th and 90th, were converted from millimeters to pixels. The model was trained to estimate the grain size in pixels, from which the size in millimeters was later recovered. 


\begin{tabular}{|l|c|c|c|c|c|c||}
\hline \hline Table 4. SediNet grain size analysis results compared with the sieve-estimated $\boldsymbol{d}_{50}$. \\
\hline \hline Site Name & \# Images & $\begin{array}{c}\text { \# Images for } \\
\text { Training and } \\
\text { Testing }\end{array}$ & $\begin{array}{c}\text { mm/pixel } \\
\text { Range }\end{array}$ & $\begin{array}{c}\text { SediNet } \boldsymbol{d} 5 \mathbf{0} \\
(\boldsymbol{\mu} \mathbf{m})\end{array}$ & $\begin{array}{c}\text { Sieve } \boldsymbol{d}_{50} \\
(\boldsymbol{\mu m})\end{array}$ & $\begin{array}{c}\text { Mean Error } \\
\boldsymbol{d}_{50}\end{array}$ \\
\hline Assateague, MD & 12 & 116 & $0.1-0.18$ & 475 & 323 & $41.2 \%$ \\
\hline Biloxi, MS & 8 & 74 & $0.01-0.04$ & 241 & 264 & $11.6 \%$ \\
\hline Calvert Cliffs, MD & 5 & 32 & $0.01-0.05$ & 336 & 305 & $18.1 \%$ \\
\hline False Cape, VA & 12 & 106 & $0.1-0.18$ & 352 & 249 & $49.3 \%$ \\
\hline Gulfport, MS & 10 & 88 & $0.02-0.05$ & 275 & 275 & $11.3 \%$ \\
\hline Ocean Springs, MS & 8 & 67 & $0.03-0.05$ & 307 & 300 & $17.2 \%$ \\
\hline Outer Banks, NC & 8 & 34 & $0.03-0.06$ & 314 & 303 & $8.4 \%$ \\
\hline Total/Mean & 63 & 517 & 0.064 & - & - & $22.4 \%$ \\
\hline
\end{tabular}

The 517-image set was split randomly into 258 images (50\%) for training the model and 257 images for testing. The SediNet model was trained following Buscombe (2020), using $1024 \times 1024$ $\times 3$ pixel imagery rather than the 512 square-pixels noted in the manuscript. A schematic of the model is shown in Figure 5. The image is fed into the network through a series of layers that are designed and trained to automatically detect image features that can be used to estimate grain size using a separate multi-layer perceptron for each estimated grain-size percentile. The back propagation algorithm is used to optimize the weights of the feature extractor layers using an iterative procedure to minimize observed-estimated grain size discrepancy. The model was evaluated by comparing the mean percent difference in observed and estimated grain sizes over the 257-image test set. Table 4 summarizes model accuracy for the $d_{50}$ at the seven sites, as well as overall accuracies. Figure 6 shows that the model tends to overpredict the size of the finest grains. This could be due to image resolution issues where the grains are so small they are subpixel or otherwise the lack of distinction between adjacent grains or interstices. This tends to manifest when grain sizes are less than three pixels. The same limitation is known to severely affect grain size results using the wavelet method. One consequence of having variably scaled imagery is the necessity to compute all grain sizes in pixels, then convert back to equivalent sieve sizes using the scaling of each image. There is a significant variability in error per site (Figure 6 and Table 4), ranging from $8 \%$ to $50 \%$ with a mean of $22 \%$. This is likely because of the variability in both beach sedimentology and image resolution from the camera setup. Images from Assateague and False Cape were up to four and one-half times lower resolution than the other images. 


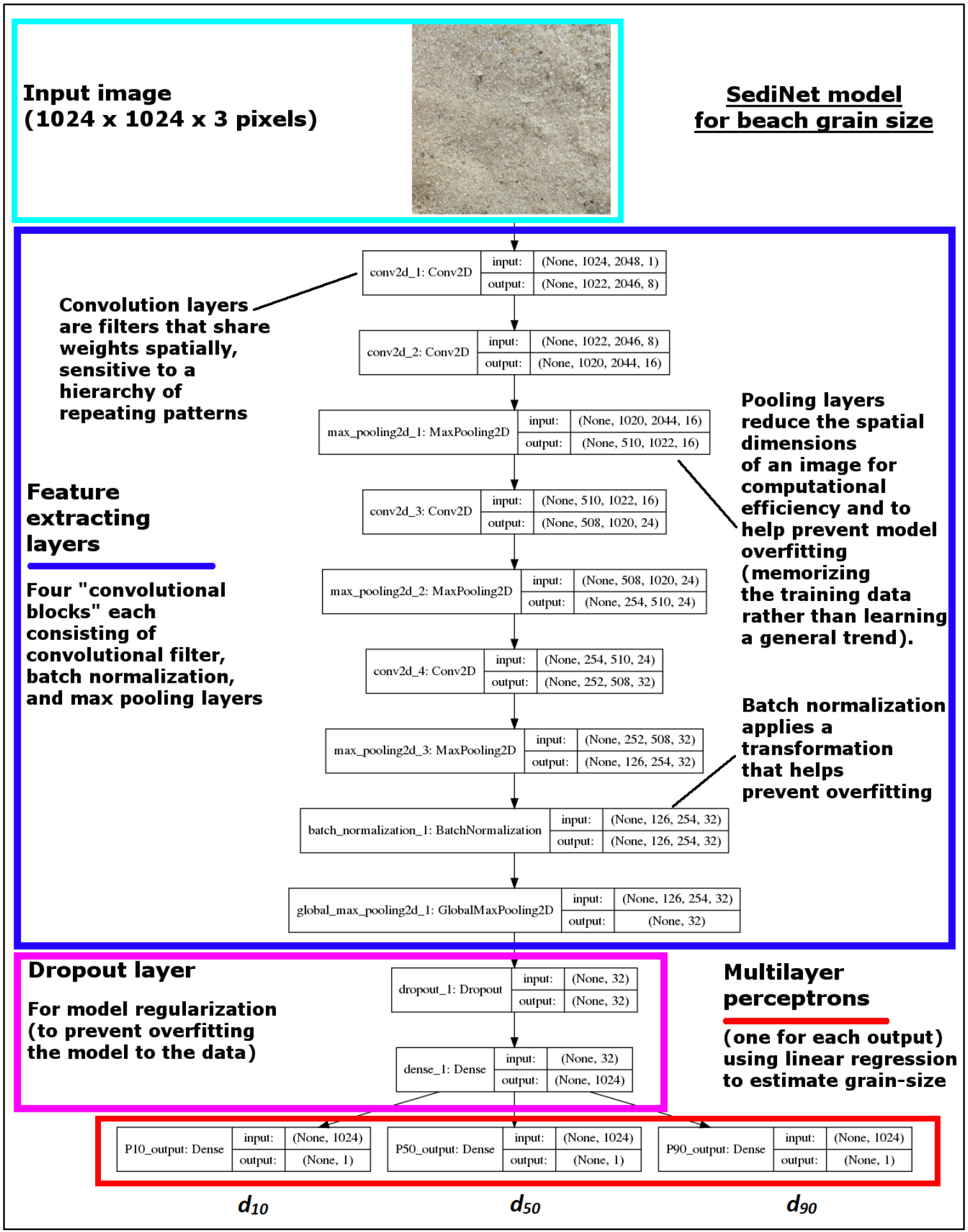

Figure 5. A schematic of the SediNet model implementation used in this study. Numbers in input and output layers correspond to the size in pixels of the image features used by that layer. By the final layer, the information in the image has been reduced to a vector of length 1024 that is used to make grain size predictions. 

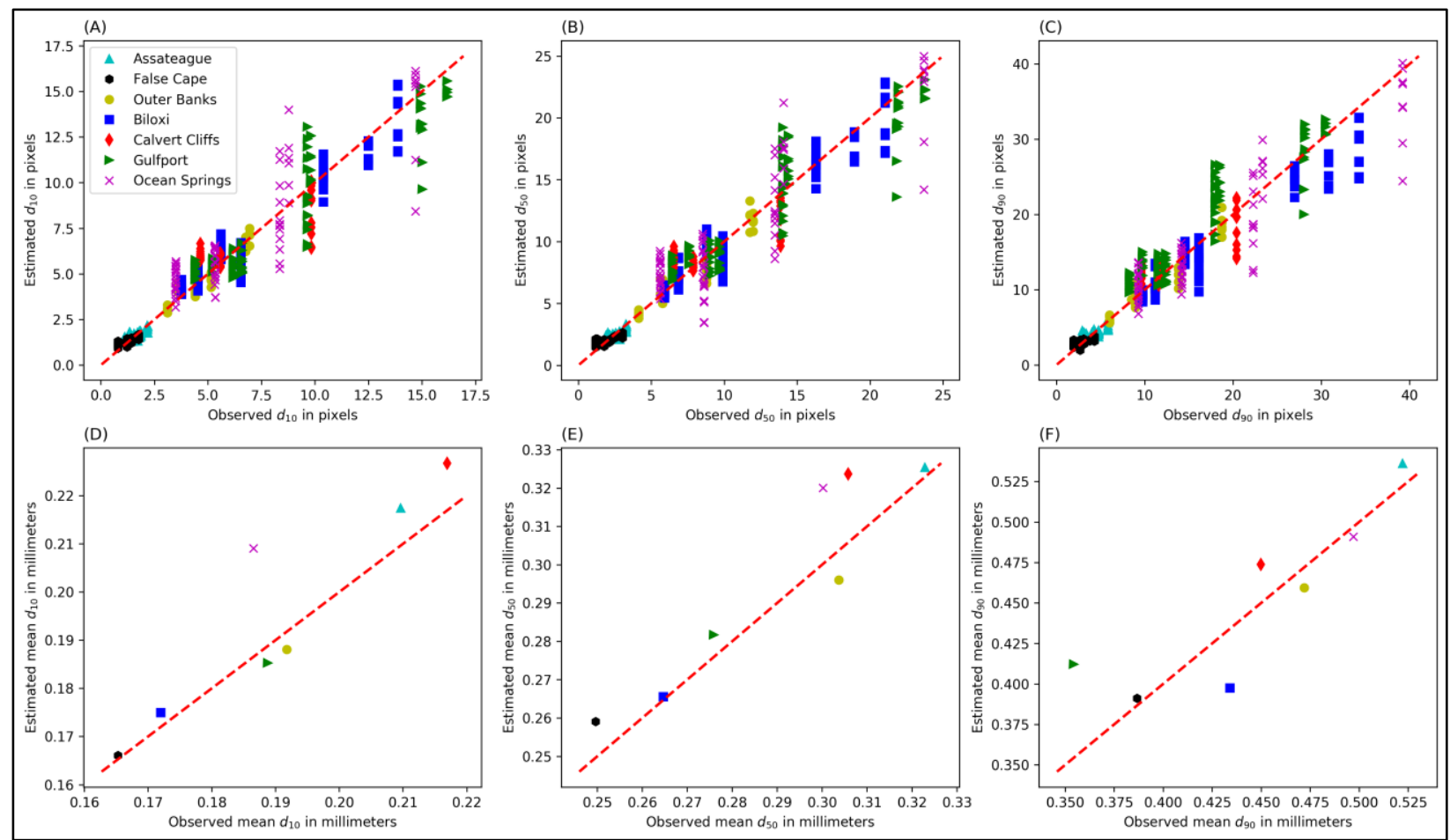

Figure 6. Observed versus estimated grain size in pixels for the (A) $d 10,(B) d 50$, and (C) $d 90$, and (D-F) average estimated grain size in millimeters for the seven sites detailed in Table 4. Dashed line is the $1: 1$ relationship.

In the future with sufficient data, the results here and in Buscombe (2020) strongly suggest that per-site (or similar groups of sites) models would be more accurate. The current model estimates average beach $d_{50}$ to within $20 \%$ at five out of the seven sites. This error range is similar to the results of the wide sedimentological spectrum of well and poorly sorted sediment tested in Buscombe (2020).

Physical Shipment and Analysis. The physical shipment method is the least cost effective but may have the best accuracy. With this technique, the citizen scientist would physically collect a sample, note the location the sample was taken, and mail it in to a central location for analysis. Pre-paid mailing containers could be distributed to encourage this method. This method would be appropriate if periodically used in conjunction with one of the other image-based techniques to update and validate the results.

\section{ACCURACY OF THE CELL PHONE GLOBAL POSITIONING SYSTEM (GPS):} GPS-enabled smartphones provide a convenient, low-cost way for the public to collect location data. The accuracy of the GPS unit used by citizen scientists in this data collection effort is a potential source of error that needs to be evaluated. Other researchers have tried to estimate the error associated with the horizontal location provided by smartphones. The results vary but are generally less than $5 \mathrm{~m}$. For example, Tomastik et al. (2017) found cellphones (Android 2.3, 4.4, $5.0)$ to have an error less than $2.36 \mathrm{~m}$ (horizontal) under open-area conditions. In another study, Schaefer and Woodyer (2015) found the absolute accuracy to range between 2.64 to $4.19 \mathrm{~m}$. The Schaefer and Woodyer study included iPhones, Samsung, and Sony phones and found no difference among the phones. Data for this project would be collected from the beach with no tree 
cover. Thus, less than $5 \mathrm{~m}$ accuracy is expected. The cross-shore variability of the beach grain size between morphological features (e.g., dune, berm, swash) can be significant, but the morphological features are generally larger than $5 \mathrm{~m}$, making the cell phone's GPS accurate enough for crowdsourcing data. To minimize the potential error induced by the cell phone GPS accuracy on the grain size studies, the cross-shore morphological feature where the image is taken should be noted.

SCHOOL AND CITIZEN ENGAGEMENT: Citizen science projects offer an opportunity for students to participate in an authentic research experience. This can increase confidence in a student's ability and foster an appreciation for the scientific process. The Next Generation Science Standards allow educators and students to spend more time analyzing data (National Research Council 2012). The database will provide an opportunity for students to learn science and engineering practices defined by the Next Generation Science Standards, such as the following:

- $\quad$ asking questions

- planning and carrying out investigations

- analyzing and interpreting data

- using mathematical and computational thinking

- constructing explanation

- engaging in argument from evidence

- obtaining, evaluating, and communicating information.

The dataset provides an opportunity for students in coastal areas to collect data and for students everywhere to have access to the data to conduct studies. This database could be used by students to create and test hypotheses about why grain size varies. For example, students might believe that wave size controls sediment size. They could test this hypothesis with the database and wave characteristic data from the National Data Buoy Center. Additionally, students might assume grain size is related to the width of the continental shelf. They could test this with the grain size database and a bathymetric map of the ocean. In summary, this crowdsourcing methodology could be used as a bridge between research scientists and educators to extend authentic research opportunities to students and the general public while bolstering data records that can inform research.

SUMMARY: The feasibility of engaging citizen scientists in the collection of meaningful beach grain size information has been investigated and determined to be achievable. The proposed methodology involves citizen scientists uploading imagery from which grain size information would be extracted and returned to a public database. Three techniques for determining grain size from beach sediment imagery were investigated: geometrical analysis, statistical analysis, and machine learning. With the geometric analysis, grain size was estimated by thresholding imagery and separating individual grains with watershed segmentation. Geometrical analysis estimated $d_{50}$ from in situ imagery with an average error of 34\% and from imagery of carefully prepared sediment samples with an average error of $24 \%$. Identifying individual particles in citizen scientist imagery of beach sediment using geometric analysis is expected to require some user input. Grain size was also estimated by determining relevant length scales of pixel intensity variations with wavelet-derived power spectra to investigate statistical approaches to optical granulometry. A wavelet based tool (pyDGS) estimated $d_{50}$ from citizen scientist style imagery of beach sediment with an average error of $36 \%$. The final method of estimating sediment size in this study was machine learning. A machine learning model (SediNet) trained on citizen scientist style imagery 
of beach sediment estimated the $d_{50}$ of beach sediment with errors less than $20 \%$ at five out of seven sites. The sites with more than $20 \%$ error had significantly lower resolution images.

Based on the results of this feasibility study, the machine learning technique using SediNet will continue to be used and developed for use with imagery collected by citizen scientists. Results from the high-resolution images using this technique had less error than the preferred maximum error of $25 \%$. Additionally, the SediNet model will continue to be trained as additional images and physical samples are collected to improve its accuracy and robustness. A framework to house crowdsourced imagery and an interactive website to engage citizen scientists will be developed. Crowdsourcing scientific data collection offers an opportunity to encourage involvement in the scientific process and foster interest in coastal science while acquiring data on a very large geographic scale with the potential to address new and exciting topics.

ADDITIONAL INFORMATION: This CHETN was prepared as part of the US Army Corps of Engineers (USACE) Coastal Inlets Research Program (CIRP) by Brian C. McFall, David L. Young, Kelsey A. Fall, and Douglas R. Krafft, US Army Engineer Research and Development Center (ERDC), Coastal and Hydraulics Laboratory (CHL), Vicksburg, MS; Shelley J. Whitmeyer and Alesha E. Melendez of James Madison University; and Daniel Buscombe of Marda Science, LLC. Questions pertaining to this CHETN may be directed to Brian McFall (Brian.C.McFall@usace.army.mil), David Young (David.L.Young@usace.army.mil), Shelley Whitmeyer (whitm2sj@jmu.edu), or the USACE CIRP Program Manager, Tanya M. Beck (Tanya.M.Beck@usace.army.mil). Additional information regarding CIRP may be obtained from the CIRP web site http://cirp.usace.army.mil/.

This ERDC/CHL CHETN should be cited as follows:

McFall, B. C., D. L. Young, K. A. Fall, D. R. Krafft, S. J. Whitmeyer, A. E. Melendez, and D. Buscombe. 2020. Technical Feasibility of Creating a Beach Grain Size Database with Citizen Scientists. CHETN ERDC/CHL-IV-125. Vicksburg, MS: US Army Engineer Research and Development Center. http://dx.doi.org/10.21079/11681/36456

\section{REFERENCES}

Bascom, W. N. 1951. "The Relationship between Sand Size and Beach-Face Slope.” Transactions American Geophysical Union 32(6): 866-874.

Bauer-Civiello, A., J. Loder, and M. Hamann. 2018. "Using Citizen Science Data to Assess the Difference in Marine Debris Loads on Reefs in Queensland, Australia." Marine Polution Bulletin 135: 458-465.

Buscombe, D. 2013. "Transferable Wavelet Method for Grain-Size Distribution from Images of Sediment Surfaces and Thin Sections, and Other Natural Granular Patterns." Sedimentology 60: 1709-1732.

Buscombe, D. 2020. "SediNet: A Configurable Deep Learning Model for Mixed Qualitative and Quantitative Optical Granulometry." Earth Surface Processes and Landforms 45: 638-651.

Buscombe, D., and G. Masselink. 2009. "Grain-Size Information from the Statistical Properties of Digital Images of Sediment.” Sedimentology 56(2): 421-438. 
Buscombe, D., D. M. Rubin, and J. A. Warrick. 2010. "A Universal Approximation of Grain Size from Images of Noncohesive Sediment." Journal of Geophysical Research 115: F02015. doi: 0.1029/2009JF001477

Carbonneau, P. E. 2005. "The Threshold Effect of Image Resolution on Image-Based Automated Grain Size Mapping in Fluvial Environments." Earth Surface Processes and Landforms 30: 1687-1693.

Carbonneau, P. E., S. N. Lane, and N. Bergeron. 2004. "Catchment Scale Mapping of Surface Grain Size in Gravel Bed Rivers Using Airborne Digital Imagery.” Water Resources Research 40(7): W07202.

Gallagher, E. L., J. MacMahan, A. J. H. M. Reniers, J. Brown, and E. B. Thornton. 2011. "Grain Size Variability on a Rip-Channeled Beach." Marine Geology 287: 43-53.

Gonzalez, R. C., R. E. Woods, and S. L. Eddins. 2004. Digital Image Processing Using Matlab. Pearson Prentice Hall.

Graham, D. J., I. Reid, and S. P. Rice. 2005. “Automated Sizing of Coarse-Grained Sediments: ImageProcessing Procedures." Mathematical Geology 37(1): 1-28 .

Gura, T. 2013. “Citizen Science: Amateur Experts.” Nature 496(7444): 259-261.

Hallermeier, R. J. 1981. “A Profile Zonation for Seasonal Sand Beaches from Wave Climate.” Coastal Engineering 4:253-277.

Harley, M. D., M. A. Kinsela, E. Sánchez-García, and K. Vos. 2019. "Shoreline Change Mapping Using Crowd-Sourced Smartphone Images.” Coastal Engineering 150:175-189.

Irwin, A. 2018. "No PhDs Needed: How Citizen Science is Transforming Research.” Nature 562: 480482.

Kornilov A. S., and I. V. Safonov. 2018. "An Overview of Watershed Algorithm Implantations in Open Source Libraries.” Journal of Imaging 2018(4): 123. doi: 10.3390/jimaging4100123

Li, M., D. Wilkinson, and K. Patchigolia. 2005. "Comparison of Particle Size Distributions Measured Using Different Techniques.” Particulate Science and Technology 23: 265-284.

Luijendijk, A., G. Hagenaars, R. Ranasinghe, F. Baart, G. Donchyts, and S. Aarninkhof. 2018. "The State of the World's Beaches." Scientific Reports 8(1): 6641.

McFall, B. C., and K. E. Brutsché. 2018. User's Guide for the Sediment Mobility Tool Web Application. ERDC/TN RSM-18-4. Vicksburg, MS: US Army Engineer Research and Development Center.

McFall, B. C., S. J. Smith, C. E. Pollock, J. Rosati, III, and K. E. Brutsché. 2016. Evaluating Sediment Mobility for Siting Nearshore Berms. ERDC/CHL CHETN-IV-108. Vicksburg, MS: US Army Engineer Research and Development Center.

National Research Council. 2012. A Framework for K-12 Science Education: Practices, Crosscutting Concepts, and Core Ideas. Committee on a Conceptual Framework for New K-12 Science Education Standards. Board on Science Education, Division of Behavioral and Social Sciences and Education. Washington, DC: The National Academies Press.

Otsu, N. 1979. "A Threshold Selection Method from Gray-Level Histogram." IEEE Transactions on System Man Cybernetics 9: 62-66.

Prodger, S., P. Russell, M. Davidson, J. Miles, and T. Scott. 2016. "Understanding and Predicting the Temporal Variability of Sediment Grain Size Characteristics on High-Energy Beaches." Marine Geology 376:109-117.

Rubin, D. M. 2004. "A Simple Autocorrelation Algorithm for Determining Grain Size from Digital Images of Sediment." Journal of Sedimentary Research 74(1): 160-165. 
Schaefer, M., and T. Woodyer. 2019. "Assessing Absolute and Relative Accuracy of Recreation-Grade and Mobile Phone GNSS Devices: A Method for Informing Device Choice.” Area 47(2): 185-196.

Sime, L. C., and R. I. Ferguson. 2003. "Information on Grain Sizes in Gravel-Bed Rivers by Automated Image Analysis.” Journal of Sedimentary Research 73(4): 630-636.

Soulsby, R. L. 1997. Dynamics of Marine Sands: A Manual for Practical Application. London, England: Thomas Telford Publications.

Tomaštík, J., Jr., Š. Salon, and R. Piroh. 2017. "Horizontal Accuracy and Applicability of Smartphone GNSS Positioning in Forests.” Forestry 90(2): 187-98.

USACE (US Army Corps of Engineers). 2002. "Longshore Sediment Transport." Coastal Engineering Manual. EM 1110-2-1100. Washington, DC: US Army Corps of Engineers.

Warrick, J. A., D. M. Rubin, P. Ruggiero, J. N. Harney, A. E. Draut, and D. Buscombe. 2009. "Cobble Cam: Grain-Size Measurements of Sand to Boulder from Digital Photographs and Autocorrelation Analyses." Earth Surface Processes and Landforms 34(13): 1811-1821.

NOTE: The contents of this technical note are not to be used for advertising, publication, or promotional purposes. Citation of trade names does not constitute an official endorsement or approval of the use of such products. 